\title{
Editorial
}

Shali Mazaki-Tovi and Edi Vaisbuch*

\section{Clinical chorioamnionitis - an ongoing obstetrical conundrum}

DOI 10.1515/jpm-2015-0366

The clinical entity of intrapartum fever, the hallmark sign of clinical chorioamnionitis, has been known for centuries [1]. As early as the late $18^{\text {th }}$ century it was precisely defined as any fever arising in consequences of pregnancy or delivery [2]. The grave consequences of this condition were well known to the physicians at that time as attested by the comment of John Leake of the New Westminster Lying-in Hospital in 1772: "If those diseases which have been found most dangerous and mortal in their effects ought principally to be considered by physicians, none will more deservedly engage their attention than the Childbed Fever, as there is not, perhaps, any malady..." [3].

The criteria for the diagnosis of clinical chorioamnionitis include fever and two or more of the following: maternal and fetal tachycardia, uterine tenderness, foul smelling amniotic fluid, and maternal leukocytosis [4-13]. These criteria have been used in clinical practice since the early 70 s of the previous century. When it comes to management and understanding of the pathophysiology of intrapartum fever and clinical chorioamnionitis, a walk into labor and delivery ward today can be like taking a step back to the 70s. Admittedly, with regard to intrapartum fever, our discipline, which was awarded the wooden spoon by Archie Cochrane for being the least evidence based medical specialty [14], has not done enough yet to restore its reputation.

The association between short- and long-term adverse neonatal outcomes and chorioamnionitis are well established [11, 15-39], with neonatal sepsis and cerebral palsy being the most noteworthy [17, 21]. This issue of the Journal shed new light on the ongoing clinical challenge of diagnosis and management of chorioamnionitis at term. Using state-of-the-art methods and unique study and control population, this set of articles [40-44] provides a wealth of novel and important information and can be viewed as the first genuine and comprehensive attempt to decipher the enigma of clinical chorioamnionitis. These articles challenge the diagnosis, the underlying mechanism of disease and indeed, the very definition of clinical chorioamnionitis at term. Precision in diagnosis and taxonomy, as well as the molecular mechanism(s) responsible for this common and important complication may have preventive, diagnostic and therapeutical implications. Similarly important is to avoid over diagnosis which leads to unnecessary, potentially harmful, treatment and interventions. The urgent need to improve the knowledge in this important subject is evident as the human fetus is probably most vulnerable during labor and delivery and that these complications should be regarded as preventable.

The initial report [45] by Romero's group recently published in this Journal challenges the clinical diagnosis of chorioamnionitis at term. Using both cultivation and molecular techniques of amniotic fluid, almost $40 \%$ of women clinically diagnosed with chorioamnionitis did not have any evidence of bacteria in the amniotic cavity. Notably, nearly $50 \%$ did not have evidence of acute inflammatory lesions of the placenta (i.e. histologic chrioamnionitis [46]).

In the first report [40] of the series of articles published in this special issue of the Journal, the authors characterized the intra-amniotic inflammatory response in women with clinical chorioamnionitis at term. Expectably, women with intra-amniotic infection and/or inflammation had significantly higher concentrations of pro- and anti-inflammatory cytokines and chemokines compared to women at term in labor without intra-amniotic inflammation. Yet, although diagnosed with clinical chorioamnionitis, patients without intra-amniotic inflammation had a similar amniotic fluid expression of cytokines/chemokines to normal women in labor at term [40].

The next step was to demonstrate how well the different clinical criteria used for the diagnosis of chorioamnionitis perform in the identification of proven intra-amniotic infection [41]. Not surprisingly, none of the individual clinical signs, or any of their combination, accurately identified patients with intra-amniotic infection or microbial-associated intra-amniotic inflammation. Thus, there is a need for better methods to enhance our precision in the clinical diagnosis of chorioamnionitis at term. 
These results lead the authors to focus their interest in the maternal compartment to characterize the plasma cytokine profile [42]. Using cutting edge methods, the authors demonstrate that patients with clinical chorioamnionitis at term have higher maternal plasma concentrations of pyrogenic cytokines than patients in spontaneous labor at term without a fever. However, the absolute concentration of cytokines cannot be used to identify those who have bacteria in the amniotic fluid, suggesting that amniotic fluid assessment is required to identify women with intra-amniotic inflammation.

Next, the authors focused their attention to the fetus [43] and placenta [44]. Characterization of inflammatory status in dyads of maternal-fetal samples revealed that neonates born to mothers with clinical chorioamnionitis at term had higher concentrations of umbilical cord plasma cytokines than those born to mothers without clinical chorioamnionitis. This inflammatory "mirror syndrome" was anticipated. However, less predictable is the finding that even neonates exposed to clinical chorioamnionitis without intra-amniotic inflammation had elevated concentrations of inflammatory cytokines. This suggests that intrapartum fever, per se, is associated with an altered fetal immune response. Thus, antibiotics administration, which is the mainstay of treatment in patients with intrapartum fever [9, 47-50], may be too little and too late. The role of other therapeutic strategies such as anti-inflammatory agents should be investigated in this clinical set-up [51, 52].

The conventional wisdom is that histology is the "gold standard" for the diagnosis of chorioamnionitis. Nevertheless, despite the association between histologic chorioamnionitis/funisitis and intra-amniotic infection/ fetal inflammatory response syndrome [53-55], the performance indices of histology were surprisingly low [44]. The practical conclusion is that the current pathologic methods have limitations in the identification of the fetus exposed to amniotic cavity infection. One way to look at the placenta is as the "black-box" of the pregnancy. However, in contrast to chorioamnionitis in preterm gestations, in the context of term deliveries, the time interval between the occurrence of clinical chorioamnionitis and the delivery of the placenta may be too short for the placenta to "record" the insult.

The term "clinical chorioamnionitis" is an oxymoron. As the name implies, diagnosis of chorioamnionitis is based on histological evaluation of the placenta. However, the prefix "clinical" means that the diagnosis should be made well before the delivery of the placenta. The articles in this special issue of the Journal bridge the gap and attempt to ease the inherent tension between the "clinical" and the "chorioamnionitis".

\section{References}

[1] DeLacy M. Puerperal fever in eighteenth-century Britain. Bull Hist Med. 1989;63:521-56.

[2] Kirkland T. A treatise on childbed fevers and the methods of preventing them. FC 1774:283.

[3] Leake J. Practical observations on the Childbed fever. FC 1772:117.

[4] MacVicar J. Chorioamnionitis. Clin Obstet Gynecol. 1970;13:272-90.

[5] Gibbs RS. Diagnosis of intra-amniotic infection. Semin Perinatol. 1977;1:71-7.

[6] Gibbs RS, Castillo MS, Rodgers PJ. Management of acute chorioamnionitis. Am J Obstet Gynecol. 1980;136:709-13.

[7] Gibbs RS, Blanco JD, St Clair PJ, Castaneda YS. Quantitative bacteriology of amniotic fluid from women with clinical intraamniotic infection at term. J Infect Dis. 1982;145:1-8.

[8] Hollander D. Diagnosis of chorioamnionitis. Clin Obstet Gynecol. 1986;29:816-25.

[9] Gibbs RS, Dinsmoor MJ, Newton ER, Ramamurthy RS. A randomized trial of intrapartum versus immediate postpartum treatment of women with intra-amniotic infection. Obstet Gynecol. 1988;72:823-8.

[10] Gilstrap LC, 3rd, Cox SM. Acute chorioamnionitis. Obstet Gynecol Clin North Am. 1989;16:373-9.

[11] Newton ER. Chorioamnionitis and intraamniotic infection. Clin Obstet Gynecol. 1993;36:795-808.

[12] Tita AT, Andrews WW. Diagnosis and management of clinical chorioamnionitis. Clin Perinatol. 2010;37:339-54.

[13] Romero R, Dey SK, Fisher SJ. Preterm labor: one syndrome, many causes. Science 2014;345:760-5.

[14] Godlee F. Obstetrics and the wooden spoon. Br Med J. 2012;345:e7017.

[15] Yoder PR, Gibbs RS, Blanco JD, Castaneda YS, St Clair PJ. A prospective, controlled study of maternal and perinatal outcome after intra-amniotic infection at term. Am J Obstet Gynecol. 1983;145:695-701.

[16] Nelson KB, Ellenberg JH. Antecedents of cerebral palsy. I. Univariate analysis of risks. Am J Dis Child. 1985;139:1031-8.

[17] Grether JK, Nelson KB. Maternal infection and cerebral palsy in infants of normal birth weight. J Am Med Assoc. 1997;278:207-11.

[18] Alexander JM, McIntire DM, Leveno KJ. Chorioamnionitis and the prognosis for term infants. Obstet Gynecol. 1999;94:274-8.

[19] Yoon BH, Romero R, Kim KS, Park JS, Ki SH, Kim BI, et al. A systemic fetal inflammatory response and the development of bronchopulmonary dysplasia. Am J Obstet Gynecol. 1999;181:773-9.

[20] Yoon BH, Romero R, Park JS, Kim C], Kim SH, Choi JH, et al. Fetal exposure to an intra-amniotic inflammation and the development of cerebral palsy at the age of three years. Am J Obstet Gynecol. 2000;182:675-81. 
[21] Wu YW, Colford, JM Jr. Chorioamnionitis as a risk factor for cerebral palsy: a meta-analysis. J Am Med Assoc. 2000;284:1417-24.

[22] Wu YW, Escobar G], Grether JK, Croen LA, Greene JD, Newman TB. Chorioamnionitis and cerebral palsy in term and near-term infants. J Am Med Assoc. 2003;290:2677-84.

[23] Mittendorf R, Covert R, Montag AG, elMasri W, Muraskas J, Lee KS, et al. Special relationships between fetal inflammatory response syndrome and bronchopulmonary dysplasia in neonates. J Perinat Med. 2005;33:428-34.

[24] Bashiri A, Burstein E, Mazor M. Cerebral palsy and fetal inflammatory response syndrome: a review. J Perinat Med. 2006;34:5-12.

[25] Lee SE, Romero R, Jung H, Park CW, Park JS, Yoon BH. The intensity of the fetal inflammatory response in intraamniotic inflammation with and without microbial invasion of the amniotic cavity. Am J Obstet Gynecol. 2007;197:294 e1-6.

[26] Korzeniewski SJ, Romero R, Cortez J, Pappas A, Schwartz AG, Kim CJ, et al. A "multi-hit" model of neonatal white matter injury: cumulative contributions of chronic placental inflammation, acute fetal inflammation and postnatal inflammatory events. J Perinat Med. 2014;42:731-43.

[27] Horvath B, Lakatos F, Tóth C, Bödecs T, Bódis J. Silent chorioamnionitis and associated pregnancy outcomes: a review of clinical data gathered over a 16-year period. J Perinat Med. 2014;42:441-7.

[28] Bastek JA, Weber AL, McShea MA, Ryan ME, Elovitz MA. Prenatal inflammation is associated with adverse neonatal outcomes. Am J Obstet Gynecol. 2014;210:450 e1-10.

[29] Combs CA, Gravett M, Garite TJ, Hickok DE, Lapidus ], Porreco R, et al. Amniotic fluid infection, inflammation, and colonization in preterm labor with intact membranes. Am J Obstet Gynecol. 2014;210:125 e1-125 e15.

[30] Kacerovsky M, Musilova I, Andrys C, Hornychova H, Pliskova L, Kostal M, et al. Prelabor rupture of membranes between 34 and 37 weeks: the intraamniotic inflammatory response and neonatal outcomes. Am J Obstet Gynecol. 2014;210:325 e1-325 e10.

[31] Boyer A, Cameron L, Munoz-Maldonado Y, Bronsteen R, Comstock CH, Lee W, Goncalves LF. Clinical significance of amniotic fluid sludge in twin pregnancies with a short cervical length. Am J Obstet Gynecol. 2014;211:506 e1-9.

[32] Cobo T, Kacerovsky M, Jacobsson B. Amniotic fluid infection, inflammation, and colonization in preterm labor with intact membranes. Am J Obstet Gynecol. 2014;211:708.

[33] Stanek J, Biesiada J. Relation of placental diagnosis in stillbirth to fetal maceration and gestational age at delivery. J Perinat Med. 2014;42:457-71.

[34] Armstrong-Wells J, Donnelly M, Post MD, Manco-Johnson MJ, Winn VD, Sébire G. Inflammatory predictors of neurologic disability after preterm premature rupture of membranes. Am J Obstet Gynecol. 2015;212:212 e1-9.

[35] Kim CJ, Romero R, Chaemsaithong P, Kim JS. Chronic inflammation of the placenta: definition, classification, pathogenesis, and clinical significance. Am J Obstet Gynecol. 2015;213(4 Suppl):S53-69.

[36] Mir IN, Johnson-Welch SF, Nelson DB, Brown LS, Rosenfeld CR, Chalak LF. Placental pathology is associated with severity of neonatal encephalopathy and adverse developmental outcomes following hypothermia. Am J Obstet Gynecol. 2015. doi: 10.1016/j.ajog.2015.09.072.
[37] Wong LF, Holmgren CM, Silver RM, Varner MW, Manuck TA. Outcomes of expectantly managed pregnancies with multiple gestations and preterm premature rupture of membranes prior to 26 weeks. Am J Obstet Gynecol. 2015;212:215 e1-9.

[38] Lee Y, Kim HJ, Choi SJ, Oh SY, Kim JS, Roh CR, et al. Is there a stepwise increase in neonatal morbidities according to histological stage (or grade) of acute chorioamnionitis and funisitis?: effect of gestational age at delivery. J Perinat Med. 2015;43:259-67.

[39] Romero R, Grivel JC, Tarca AL, Chaemsaithong P, Xu Z, Fitzgerald W, et al. Evidence of perturbations of the cytokine network in preterm labor. Am J Obstet Gynecol. 2015. doi: 10.1016/j.ajog.2015.07.037.

[40] Romero R, Chaemsaithong P, Korzeniewski SJ, Tarca AL, Bhatti G, Xu Z, et al. Clinical chorioamnionitis at term II: the intra-amniotic inflammatory response. J Perinat Med. 2016;44:5-22.

[41] Romero R, Chaemsaithong P, Korzeniewski SJ, Kusanovic JP, Docheva N, Martinez-Varea A, et al. Clinical chorioamnionitis at term III: how well do clinical criteria perform in the identification of proven intra-amniotic infection? J Perinat Med. 2016;44:23-32.

[42] Romero R, Chaemsaithong P, Docheva N, Korzeniewski SJ, Tarca AL, Bhatti G, et al. Clinical chorioamnionitis at term IV: the maternal plasma cytokine profile. J Perinat Med. 2016;44:77-98.

[43] Romero R, Chaemsaithong P, Docheva N, Korzeniewski S], Tarca AL, Bhatti G, et al. Clinical chorioamnionitis at term V: umbilical cord plasma cytokine profile in the context of a systemic maternal inflammatory response. J Perinat Med. 2016;44:53-76.

[44] Romero R, Chaemsaithong P, Docheva N, Korzeniewski SJ, Kusanovic JP, Yoon BH, et al. Clinical chorioamnionitis at term VI: acute chorioamnionitis and funisitis according to the pres ence or absence of microorganisms and inflammation in the amniotic cavity. J Perinat Med. 2016;44:33-51.

[45] Romero R, Miranda J, Kusanovic JP, Chaiworapongsa T, Chaemsaithong P, Martinez A, et al. Clinical chorioamnionitis at term I: microbiology of the amniotic cavity using cultivation and molecular techniques. J Perinat Med. 2015;43:19-36.

[46] Kim C), Romero R, Chaemsaithong P, Chaiyasit N, Yoon BH, Kim YM. Acute chorioamnionitis and funisitis: definition, pathologic features, and clinical significance. Am J Obstet Gynecol. 2015;213(4 Suppl):S29-52.

[47] Gilstrap LC, 3rd, Leveno KJ, Cox SM, Burris JS, Mashburn M, Rosenfeld CR. Intrapartum treatment of acute chorioamnionitis: impact on neonatal sepsis. Am J Obstet Gynecol. 1988;159:579-83.

[48] Maberry MC, Gilstrap 3rd, LC. Intrapartum antibiotic therapy for suspected intraamniotic infection: impact on the fetus and neonate. Clin Obstet Gynecol. 1991;34:345-51.

[49] Edwards SE, Grobman WA, Lappen JR, Winter C, Fox R, Lenguerrand $E$, et al. Modified obstetric early warning scoring systems (MOEWS): validating the diagnostic performance for severe sepsis in women with chorioamnionitis. Am J Obstet Gynecol. 2015;212:536 e1-8.

[50] Saccone G, Berghella V. Antibiotic prophylaxis for term or near-term premature rupture of membranes: metaanalysis of randomized trials. Am J Obstet Gynecol. 2015;212:627 e1-9.

[51] Wang B, Navath RS, Menjoge AR, Balakrishnan B, Bellair R, Dai $\mathrm{H}$, et al., Inhibition of bacterial growth and intramniotic 
infection in a guinea pig model of chorioamnionitis using PAMAM dendrimers. Int J Pharm. 2010;395:298-308.

[52] Kannan S, Dai H, Navath RS, Balakrishnan B, Jyoti A, Janisse J, et al., Dendrimer-based postnatal therapy for neuroinflammation and cerebral palsy in a rabbit model. Sci Transl Med. 2012;4:130ra46.

[53] Gomez R, Romero R, Kusanovic JP, Mazaki-Tovi S, Pineles BL, Erez O, et al. The fetal inflammatory response syndrome. Am J Obstet Gynecol. 1998;179:194-202.

[54] Pacora P, Chaiworapongsa T, Maymon E, Kim YM, Gomez R, Yoon BH, et al. Funisitis and chorionic vasculitis: the histological counterpart of the fetal inflammatory response syndrome. J Matern Fetal Neonatal Med. 2002;11:18-25.
[55] Gotsch F, Romero R, Kusanovic JP, Mazaki-Tovi S, Pineles BL, Erez 0 , et al. The fetal inflammatory response syndrome. Clin Obstet Gynecol. 2007;50:652-83.

*Corresponding author: Prof. Edi Vaisbuch, Department of Obstetrics and Gynecology, Kaplan Medical Center, Rehovot, and The Hebrew University and Hadassah School of Medicine, Jerusalem, Israel, Tel.: +972-8-9441-225, Fax: +972-8-9411-944, E-mail: evaisbuch@gmail.com

Shali Mazaki-Tovi: Department of Obstetrics and Gynecology, Sheba Medical Center, Tel-Hashomer, Sackler School of Medicine, Tel-Aviv University, Tel Aviv, Israel 